\title{
Mitochondrial DNA diversity in two populations of Taiwanese macaque (Macaca cyclopis)
}

\author{
Jui-Hua Chu ${ }^{1}$, Yao-Sung $\mathrm{Lin}^{1}$ and Hai-Yin $\mathrm{Wu}^{2, *}$ \\ ${ }^{1}$ Institute of Ecology and Evolutionary Biology, National Taiwan University, Taipei 106, Taiwan; ${ }^{2}$ Institute of \\ Natural Resources, National Dong Hwa University, Hualien 974, Taiwan (*Corresponding author: Fax: 886- \\ 3-8633260; E-mail: hywu@mail.ndhu.edu.tw)
}

Received 24 February; accepted 28 June 2004

Key words: anthropogenic introduction, control region, Macaca cyclopis, mtDNA diversity, low-invasive sampling

\begin{abstract}
Current genetic composition of a population is influenced by site-specific demographic history. We compared genetic diversity in two populations of Taiwanese macaques (Macaca cyclopis) with different site characteristics. Mitochondrial DNA variation in 145 individuals from one central, continuous population (Yushan) and one peripheral, isolated population (Shoushan) was ascertained by sequencing and PCRSSCP of the $5^{\prime}$ end hypervariable segment of the control region amplified from hair and fecal samples. All the samples from Yushan were of the same haplotype whereas those from Shoushan fell into 13 haplotypes. The mtDNA homogeneity in Yushan may indicate a "local concentration of troops" status of the population or the result of population bottleneck in the recent past by severe hunting. The relatively higher genetic diversity in the Shoushan population was contributed by released or escaped captive macaques. In addition, a simple method for preserving fecal sample as a DNA source is also recommended in the study.
\end{abstract}

\section{Introduction}

Current genetic diversity of a population is inherited from the ancestral genetic makeup since its establishment, but has been influenced by both genetic drift and immigration over time. Macaca societies are characterized by male dispersal, female philopatry, and group fission along matrilines (Pusey and Packer 1987, Dittus 1988). Such social traits are responsible for interpopulational divergence as well as intrapopulational genetic structure when examined by maternally inherited mtDNA (Melnick and Hoelzer 1992, Hoelzer et al. 1994).

However, it is possible for local macaque populations to harbor distant mtDNA haplotypes. Such incidences occur when previously isolated lineages come into contact by range expansion (Avise et al. 1987, Taberlet et al. 1992) or when male immigrants introduce novel mtDNA haplo- types into local populations (e.g. Yoshimi and Takasaki 2003). The later case, although only a temporary event, has been used to trace male dispersal (Hoelzer et al. 1994). In addition, releasing captive monkeys into non-natal sites can be seen as an anthropogenic version of immigration. Such events are not uncommon, especially in Asian countries (e.g. Kawamoto et al. 1999, Wang and Ni 2000), but are seldom mentioned.

Macaca cyclopis is an endemic primate species in Taiwan. It inhabits a variety of forested habitats from sea level to $3400 \mathrm{~m}$ in elevation (Masui et al. 1986, Fooden and $\mathrm{Wu} 2001$ ). The majority of the island-wide populations were distributed in the mountain ranges in central Taiwan, while some populations scattered in lowland forests peripheral to the central ranges (Figure 1). In the past, forest destruction and hunting were two major threats to the survival of the species (Lee et al. 2002) and were responsible for the isolation and the shrinkage 


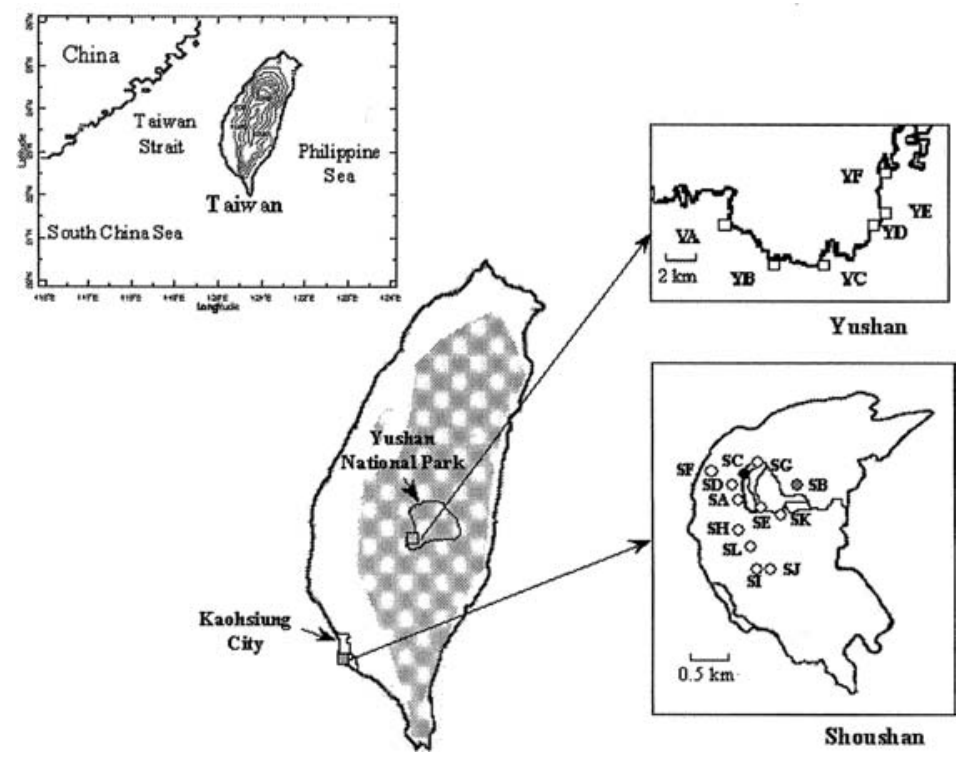

Figure 1. Map of the locations of Shoushan and Yushan in Taiwan. The distribution range of Macaca cyclopis in Taiwan is shaded. The distribution of the sampled monkey troops is also indicated. Circles indicate the sampling sites of the 12 social troops (SA $\sim$ SL) in Shoushan. Open, shaded and black circles indicate the troops where females have mtDNA haplotypes $S 1, S 2$ and $S 3$, respectively. Open squares indicate the sampling sites of the six social troops $(\mathbf{Y A} \sim \mathbf{Y F})$ along the scenic road in Yushan.

of local populations. Since around the mid-1980s, wildlife populations and their habitats have received legal protection by the enactment of Wildlife Conservation Law and the establishment of $\mathrm{Na}$ tional Parks and Wildlife Reserves. Population expansion was witnessed in some localities, which enables population study not possible before. We studied two such populations, Yushan and Shoushan, intermittently since the 1990 s.

The range of the Yushan population is within the Yushan National Park, central to the major range of M. cyclopis (Figure 1). Continuous forest tracts consisting of plantations and natural forests permit dispersal of monkeys and range expansion of social troops. The range of the Shoushan population sits along coastline suburban to the Kaohsiung metropolitan area in southern Taiwan (Figure 1). This area is peripheral to the major range of the species and has been physically isolated from any other monkey habitats by human settlements. In addition, the two populations have experienced different histories of disturbance. In Yushan, hunting and moderate habitat destruction occurred in the past decades before the establishment of Yushan National Park in 1985. On the contrary, Shoushan has served as an off-limits military base since 1941. Free access to part of the area was only possible after 1989. Past visiting restriction has provided protection to the macaque population from human disturbance.

In this study, we compared mtDNA diversity of the Yushan and Shoushan populations at two levels, diversity within social troops and intrapopulational diversity. We expected to find (1) homogeneity or low diversity within social troops in both populations according to the characteristics of Macaca society, but (2) different patterns of intrapopulational diversity in the two populations varying in site characteristics. Two alternative situations of the intrapopulational genetic diversity can be inferred from the contrasting characteristics of the two populations. When compared to Shoushan, genetic diversity in Yushan may be either higher due to the Yushan population being in the central part of the species range, or lower due to previous hunting and habitat destruction.

\section{Materials and methods}

\section{Study populations and sample collection}

The study area in Yushan situates in a mixed forest of coniferous and broadleaved trees in the western 
part of the Yushan National Park. The elevation of the area is $2300-2700 \mathrm{~m}$. The monkey population in this area has been monitored by one author (HY $\mathrm{Wu}$ ) from 1992 to 1999. At least seven troops were identified along a $25 \mathrm{~km}$ section of a scenic road. Monkeys in Yushan could not be followed continuously because of the difficult terrain of the area. Observations could only be made along the scenic road that goes through the study area.

The population in Shoushan is restricted in an isolated forest patch with an area of about $12 \mathrm{~km}^{2}$. Since this population is fully isolated from other forests by human dwellings, it is impossible for monkeys to disperse naturally. There were at lease 16 monkey troops in the area according to Hsu and Lin (2001), and most of which are habituated to human presence.

Different sample collecting strategies were employed in the two populations according to practical concerns. In Yushan, fresh fecal samples could be collected on road or along roadside when monkeys foraged on the greenbelt along the scenic road or when they crossed the road for daily movement. Such samples have been used to study the internal parasites of this population (Lin 1997). Samples used in this study were collected within 2 days during a field trip in mid-1999. Road sections frequented by specific troops were patrolled. Fecal samples left by different individuals of each social troop were collected right after the monkeys crossed the road. Although we were confident that every fecal sample came from one individual, we did not have time to label it by sex and age. Ninety-six fecal samples were collected from six monkey troops (YA to YF, bold characters are presented in the article to indicate different social troops) in Yushan (Figure 1 and Table 1). For each fecal sample, the surface was smeared with a

Table 1. Numbers of samples collected, sequenced and examined by SSCP in 18 social troops in the Yushan and Shoushan populations

\begin{tabular}{|c|c|c|c|c|c|}
\hline Population & Troop & Size & Number collected & Number sequenced & $\begin{array}{l}\text { Number Examined } \\
\text { by SSCP }\end{array}$ \\
\hline \multirow[t]{7}{*}{ Yushan } & $\mathrm{YA}^{1}$ & ca. 40 & 32 & 10 & 17 \\
\hline & YB & ca. 20 & 2 & 1 & - \\
\hline & YC & ca. 15 & 2 & 1 & - \\
\hline & YD & ca. 30 & 10 & 1 & 8 \\
\hline & YE & $>20$ & 30 & 7 & - \\
\hline & $\mathrm{YF}^{1}$ & $\mathrm{NA}^{3}$ & 20 & 2 & 18 \\
\hline & & Total & 96 & 22 & 43 \\
\hline \multirow[t]{13}{*}{ Shoushan $^{2}$} & $\mathrm{SA}^{1}$ & $49^{4}$ & $33(21 / 11)^{5}$ & 33 & \\
\hline & SB & 38 & $4(2 / 2)$ & 4 & \\
\hline & $\mathrm{SC}$ & 73 & $7(3 / 4)$ & 7 & \\
\hline & SD & 28 & $5(2 / 3)$ & 5 & \\
\hline & SE & 49 & $5(3 / 2)$ & 5 & \\
\hline & $\mathrm{SF}$ & 40 & $8(4 / 4)$ & 8 & \\
\hline & SG & 72 & $1(1 / 0)$ & 1 & \\
\hline & $\mathrm{SH}$ & 21 & $4(1 / 3)$ & 4 & \\
\hline & SI & 75 & $3(2 / 1)$ & 3 & \\
\hline & SJ & 47 & $6(4 / 2)$ & 6 & \\
\hline & SK & 66 & $3(3 / 0)$ & 3 & \\
\hline & SL & 34 & $2(1 / 1)$ & 2 & \\
\hline & & Total & $80(47 / 33)$ & 80 & \\
\hline
\end{tabular}

${ }^{1}$ Troops selected for extensive sampling to examine the assumption of a single mtDNA haplotype for members in one troop.

${ }^{2}$ All the samples collected in Shoushan were successfully amplified by PCR and were sequenced.

${ }^{3} \mathrm{NA}$, not available.

${ }^{4}$ Data of estimated troop sizes were collected by Mr CF Lin during 1998-1999.

${ }^{5}$ In the parentheses, numerators indicate numbers of sampled adult females and juveniles in the troop, and denominators indicate numbers of sampled adult males in the troop. 
sterilized swab several times and was then immersed in $1 \mathrm{~mL} 1 \mathrm{X}$ STE buffer $(10 \mathrm{mM}$ Tris- $\mathrm{HCl}$, $1 \mathrm{mM}$ EDTA, $0.1 \mathrm{M} \mathrm{NaCl} \mathrm{pH}=8.0$ ) in a $2 \mathrm{~mL}$ sample vial. Pure ethanol was poured in each vial to a total volume of $2 \mathrm{~mL}$. All samples were stored at $-20{ }^{\circ} \mathrm{C}$ after being brought back to the laboratory. In Shoushan, hair samples could be collected from monkeys of known identity in specific troops. Hairs were plucked with bare hands from juveniles and adult females. Hairs of adult males were collected by having one researcher step on the tip of a monkey's tail-hair. Once the monkey moved forward, a bunch of hairs would be left on the ground. Hair samples of 80 individuals from 12 social troops (SA to SL, Figure 1 and Table 1) were collected during 1996-1999. Samples were preserved as described in Chu et al. (1999). There were difficulties to perform exhaustive sampling for all the monkey troops. Therefore, sample size differed for each monkey troop. Few samples were collected in some troops. Extensive sampling of two troops (YA and $\mathbf{Y F}$ ) in Yushan and one troop (SA) in Shoushan were carried out to test whether there were multiple mtDNA haplotypes within troops (Table 1).

\section{$D N A$ extraction and PCR amplification}

Total genomic DNA was extracted from fecal or hair samples by the phenol-chloroform procedure (Kocher et al. 1989). The mitochondrial DNA control region was amplified by PCR. The primers used to amplify the mtDNA control region were DL1: 5'-CCAGAAATGAACACCCTTCCTAGGGC-3' (forward) designed by us, and Saru5: 5'-GCCA GGACCAAGCCTATTT-3' (reverse) designed by Hayasaka et al. (1991). The length of the PCR product is about $1.4 \mathrm{~Kb}$. The PCR mixture contained $10 \mathrm{pmol}$ of both primers, $200 \mu \mathrm{M}$ dNTP, $1.5 \mathrm{mM} \mathrm{MgCl}_{2}$, 1 X PCR reaction buffer $(20 \mathrm{mM}$ Tris- $\mathrm{HCl}, \mathrm{pH}=8.4,20 \mathrm{mM} \mathrm{KCl}$ ), 1 unit taq polymerase (Platinum $^{\mathrm{TM}}$ Taq DNA Polymerase, GIBCO BRL) and about 1-3 $\mu$ l DNA extract in a total volume of $50 \mu \mathrm{l}$. A DNA thermal cycler (Biometra) was programmed to perform an initial denaturation at $95^{\circ} \mathrm{C}$ for $10 \mathrm{~min}, 32$ cycles of 1 -min at $95{ }^{\circ} \mathrm{C}$, followed by 1 -min at $58^{\circ} \mathrm{C}$ and 2-min at $72{ }^{\circ} \mathrm{C}$. A 10 -min final extension at $72{ }^{\circ} \mathrm{C}$ was also included. PCR elutes were partially sequenced by ABI 3730 automated DNA sequencer. Samples were sequenced in both directions to detect Taq DNA polymerase errors. DL1 and another primer designed by us, DH1: 5'-CGGAGATGGGGGTGGGGGGGTTTG-3', were used as forward and reverse sequencing primers to sequence the $5^{\prime}$ end partial sequence (about $900 \mathrm{bp}$ ) of the control region. Some fecal samples were quickly examined for their haplotypes by PCR-SSCP using two other internal primers, DL2: 5'-CTATGTAATTCGTGCATTACTGC- $3^{\prime}$ and DH2: 5'-GCGGGATATTGATTTCACG GAGG-3', designed to amplify the most variable part $(350 \mathrm{bp})$ of the $5^{\prime}$ end control region. PCR-SSCP products were electrophorized on a $20 \mathrm{~cm} \times 20 \mathrm{~cm}, 6 \%$ polyacrylamide gel in a $4{ }^{\circ} \mathrm{C}$ cold room for at least $16 \mathrm{~h}$. The gels were then visualized by silver staining. In each electrophoresis, SSCP products with known haplotypes were loaded in 2-3 lanes on each gel as pattern markers.

\section{Analysis of DNA sequences}

Sequences were aligned by GCG program (Wisconsin Package Version 10.1, Genetics Computer Group, Madison, WI, USA.). The genetic distances among different mtDNA haplotypes were estimated by Kimura's two-parameter model (1980) using MEGA 2.1 package (Kumar et al. 2000). For maximum parsimony analysis, control region sequences were treated as character state data and a cladogram was constructed by PAUP $4.02 \mathrm{~b}$ (Swofford 1999) with the branch-and-bound search option. The cladogram was modified manually from a tree-like shape into a network in order to interpret relationships among different haplotypes. Minimum numbers of nucleotide changes required among connected haplotypes in the network were also calculated in PAUP.

\section{Results}

Successful PCR amplification from hair and fecal $D N A$

Amplification of mtDNA control regions was successful for all the hair samples $(\mathrm{n}=80)$ and $68 \%$ of the fecal samples $(65 / 96)$. All the hair and 22 selected fecal PCR products were sequenced. The other 43 fecal samples were examined by PCR-SSCP (Table 1). 


\section{Sequence variation of mitochondrial DNA control region}

Sequencing of $614-615$ bp of the D-loop distinguished 14 different haplotypes $(Y 1, S 1-S 13$, italic characters are presented in the article to indicate different mtDNA haplotypes) from the 102 individuals. The sequences have been deposited in GenBank under accession numbers AY014865AY014877 and AY016337. Sixty-seven of the 615 nucleotide sites $(11 \%)$ analyzed were variable. The variation includes 53 transitions, 17 transversions and one indel. Thirty-six of the 67 variable sites are parsimonious. Pairwise genetic distances of different haplotypes ranged from 0.2 to $6 \%$ (Table 2), and the mean nucleotide diversity was $3.7 \%$. PCR-SSCP products of the other 43 fecal samples showed an identical pattern as that amplified from $Y 1$ individuals. Since most of the variable sites $(53 / 67)$ were located in this $350 \mathrm{bp}$ PCR-SSCP region, we considered these 43 individuals as $Y 1$ carriers.

\section{Haplotype diversity in Yushan and Shoushan}

Contrasting results were found in haplotype diversity of the two populations. All the samples from the six troops in Yushan were of identical haplotype $(Y 1, n=65)$ whereas 13 haplotypes were found in Shoushan. Among the Shoushan haplotypes, $S 1$ was the most common. It was found in 54 of the 80 individuals. Several genetic patterns were discerned in the Shoushan population when we examined the distribution of haplotypes of adult females and juveniles and those of adult males in different troops (Table 3 ).

All the adult females and juveniles $(n=47)$ sampled from 12 troops exhibited three haplotypes $(S 1-S 3)$. Whenever there were multiple samples of adult females and juveniles in a troop, all the samples shared the same haplotype as expected. However, the distribution of the three matrilineal haplotypes among the 12 troops was uneven with S1 being the most predominant one (Figure 1 and Table 3). Males in the Shoushan population showed higher mtDNA diversity than females and juveniles. Thirteen haplotypes were found in 33 adult males. The three matrilineal haplotypes were observed in 14 adult males. The other 10 haplotypes were male-specific. Three haplotypes $(S 6, S 9$, $S 13)$ were found in three to five males, whereas each of the other seven $(S 4, S 5, S 7, S 8, S 10, S 11$, $S 12$ ) was unique to a single male. Several adult males sharing the same haplotypes were found in the same social troops. For example, four $S 1$ males were found in the troop SA and three duos in the SC, SF and SH, respectively. Similar situations were found in $S 6$ (two males in the SA and two in the SF), $S 9$ (four males in the SA), and $S 13$ (two males in the $\mathbf{S B})$.

Table 2. Percent pairwise genetic distances (Kimura's two parameter model, below the diagonal) and absolute number of nucleotide differences (above the diagonal) between the 14 haplotypes (S1 S13 in the Shoushan population and Y1 in the Yushan population)

\begin{tabular}{|c|c|c|c|c|c|c|c|c|c|c|c|c|c|c|}
\hline & $\mathrm{S} 1$ & $\mathrm{~S} 2$ & $\mathrm{~S} 3$ & S4 & S5 & S6 & S7 & S8 & S9 & $\mathrm{S} 10$ & S11 & $\mathrm{S} 12$ & $\mathrm{~S} 13$ & Y1 \\
\hline$S 1$ & - & 4 & 15 & 2 & 1 & 2 & 5 & 23 & 15 & 30 & 29 & 27 & 29 & 29 \\
\hline$S 2$ & 0.7 & - & 15 & 5 & 5 & 6 & 9 & 23 & 15 & 28 & 29 & 27 & 29 & 29 \\
\hline$S 3$ & 2.5 & 2.5 & - & 16 & 16 & 15 & 19 & 9 & 1 & 25 & 25 & 26 & 26 & 26 \\
\hline$S 4$ & 0.2 & 0.8 & 2.7 & - & 1 & 3 & 6 & 24 & 16 & 31 & 30 & 28 & 30 & 30 \\
\hline S5 & 0.2 & 0.8 & 2.7 & 0.3 & - & 3 & 5 & 24 & 16 & 31 & 30 & 28 & 30 & 30 \\
\hline S6 & 0.3 & 1.0 & 2.5 & 0.5 & 0.5 & - & 6 & 23 & 15 & 32 & 29 & 27 & 27 & 29 \\
\hline$S 7$ & 0.8 & 1.5 & 3.2 & 1.0 & 1.0 & 1.0 & - & 27 & 19 & 30 & 29 & 29 & 30 & 31 \\
\hline S8 & 3.9 & 3.9 & 1.5 & 4.0 & 4.0 & 3.9 & 4.5 & - & 8 & 32 & 32 & 35 & 35 & 35 \\
\hline S9 & 2.5 & 2.5 & 0.2 & 2.7 & 2.7 & 2.5 & 3.2 & 1.3 & - & 24 & 24 & 27 & 27 & 27 \\
\hline$S 10$ & 4.9 & 4.7 & 4.2 & 5.1 & 5.3 & 5.4 & 5.1 & 5.6 & 4.2 & - & 30 & 33 & 32 & 31 \\
\hline$S 11$ & 4.9 & 4.9 & 4.2 & 5.1 & 5.1 & 4.9 & 4.9 & 5.4 & 4.1 & 5.3 & - & 11 & 13 & 11 \\
\hline$S 12$ & 4.6 & 4.6 & 4.4 & 4.8 & 4.8 & 4.6 & 4.9 & 6.0 & 4.6 & 5.8 & 1.8 & - & 12 & 8 \\
\hline$S 13$ & 4.9 & 4.9 & 4.4 & 5.1 & 5.1 & 4.6 & 5.1 & 6.0 & 4.6 & 5.6 & 2.2 & 2.0 & - & 8 \\
\hline$Y 1$ & 4.9 & 4.9 & 4.4 & 5.1 & 5.1 & 4.9 & 5.3 & 6.0 & 4.6 & 5.4 & 1.8 & 1.3 & 1.3 & - \\
\hline
\end{tabular}


Table 3. Distribution of the 13 haplotypes in 12 social troops in the Shoushan population

\begin{tabular}{lll}
\hline Troop & Females \& Juveniles & Males \\
\hline SA & $S 1^{(21)}$ & $S 1^{(4)}, S 4^{(1)}, S 6^{(2)}, S 9^{(4)}$ \\
SB & $S 2^{(2)}$ & $S 1^{(2)}$ \\
SC & $S 3^{(3)}$ & $S 1^{(2)}, S 10^{(1)}, S 12^{(1)}$ \\
SD & $S 1^{(2)}$ & $S 3^{(1)}, S 5^{(1)}, S 6^{(1)}$ \\
SE & $S 1^{(3)}$ & $S 8^{(1)}, S 13^{(1)}$ \\
SF & $S 1^{(4)}$ & $S 1^{(2)}, S 6^{(2)}$ \\
SG & $S 1^{(1)}$ & - \\
SH & $S 1^{(1)}$ & $S 1^{(2)}, S 11^{(1)}$ \\
SI & $S 1^{(2)}$ & $S 7^{(1)}$ \\
SJ & $S 1^{(4)}$ & $S 1^{(1)}, S 2^{(1)}$ \\
SK & $S 1^{(3)}$ & - \\
SL & $S 1^{(1)}$ & $S 1^{(1)}$ \\
\hline
\end{tabular}

Number in parentheses indicates number of individuals carrying that haplotype

\section{Phylogenetic analysis}

Relationship of the 14 haplotypes is presented in a parsimonious network (Figure 2). Sequences of haplotypes $S 1, S 4, S 5$ and $S 6$ differ from each other by one to three bases, and $S 3$ differs from $S 9$ by one base. The network does not intend to reveal

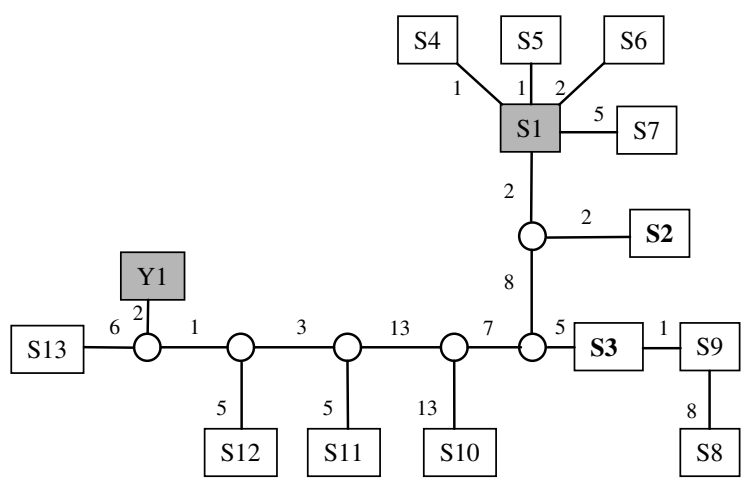

Figure 2. Parsimonious network of the relationships among the $14 \mathrm{mtDNA}$ haplotypes in Shoushan and Yushan populations. The network was modified from the cladogram constructed by PAUP 4.02b with the branch-and-bound search option. Shaded rectangles indicate native mtDNA haplotypes in Yushan and in Shoushan respectively. Open rectangles with boldfaced haplotype codes indicate possible cases of released or escaped female macaques. The other open rectangles indicate possible cases of released or escaped male macaques. Open circles indicate hypothetical ancestral states required at the branching points. Numbers along the connecting lines refer to the minimum numbers of nucleotide changes required among connected haplotypes calculated in PAUP. a phylogenetic relationship among haplotypes because samples were collected from two distant local populations. It is a simple representation to indicate an odd distribution and divergence of haplotypes in Shoushan. Interpretation for the pattern will be discussed later.

\section{Discussions}

MtDNA haplotype diversity in the two populations

MtDNA haplotypes of female macaques are generally thought, "not to vary within social troops or flow between them" (Hoelzer et al. 1994). Homogeneous mtDNA haplotype within social troops in the two populations confirmed the general genetic pattern in Macaca society (Melnick and Hoelzer 1992, Hoelzer et al. 1994). However, different intrapopulational genetic diversity reveals different demographic histories of the two populations (Table 4).

Despite being located in the central mountain range where continuous forest tracts permit dispersal and range expansion of neighboring mtDNA lineages, a paucity of mtDNA variation was found in the Yushan population. Two nonexclusive possibilities, a local concentration of troops (LCT, Kawanaka 1973) or bottleneck effect, might explain the result. A LCT could be considered as a deme or a local population. It is composed of a cluster of social troops with overlapping home ranges. The six troops may be a LCT that distributes in the central range of the $Y 1$ lineage. Since males mostly transfer between troops within a LCT (Kawanaka 1973), and longdistance dispersal has only been reported in few cases (e.g. in Yoshimi and Takasaki 2003), immigration of males carrying different haplotypes from other LCTs can be rare and difficult to detect.

The homogeneous haplotype in Yushan population may also indicate that the population has experienced a bottleneck in the past. Serious hunting pressure was imposed on many wild monkey populations in Taiwan before the implementation of the Wildlife Conservation Law. A small population caused by hunting has also been mentioned elsewhere in Kenting, southern Taiwan (Wu et al. 1991, Wu and Lin 1992). The monkey population in Yushan might have diminished to a 
Table 4. Population characteristics and possible demographic histories of Yushan and Shoushan macaques

\begin{tabular}{|c|c|c|c|c|c|}
\hline \multirow[t]{3}{*}{ Population } & \multirow[t]{3}{*}{ Past hunting pressure } & \multicolumn{3}{|c|}{ Genetic diversity $^{1}$} & \multirow[t]{3}{*}{ Demographic histories } \\
\hline & & \multicolumn{2}{|c|}{ Intrapopulation } & \multirow[b]{2}{*}{ Interpopulation } & \\
\hline & & Within troop & Among troops & & \\
\hline Yushan & Moderate to high & 0 & 0 & $1.3-6.0 \%$ & A LCT unit or bottleneck \\
\hline Shoushan & Low & $0^{2}$ & $\begin{array}{l}0.7-2.5 \%{ }^{3}(S 1-S 3) \\
0.2-6.0 \%{ }^{4}(S 1-S 13)\end{array}$ & & Anthropogenic introduction \\
\hline
\end{tabular}

\footnotetext{
${ }^{1}$ Genetic diversity is indicated by the range of pair-wise genetic distances estimated by Kimura's two parameter model (Kimura 1980).

${ }^{2}$ Genetic distance between adult females and juveniles of the same troop.

${ }^{3}$ Genetic distances between adult females and juveniles of different troops.

${ }^{4}$ Genetic distance between monkeys (adult males, adult females and juveniles) of different troops.
}

small size, leading to fixation of mtDNA haplotype. The bottleneck hypothesis could be further evaluated by studying the genetic diversity in other macaque populations within the central part of the species distribution range that could have been more protected from habitat destruction and hunting than the Yushan population.

Contrary to the homogeneous genetic structure in Yushan, Shoushan harbored diverse mtDNA haplotypes. In general, the genetic difference of the control region within a mammal population was less than $2 \%$ no matter what distance estimation method was used. For example, intrapopulational genetic distances of sika deer (Cervus nippon) estimated by the Kimura-2-parameter method were $0.2-0.6 \%$ (Nagata et al. 1999); nucleotide diversities were 1.2 and $1.1 \%$ within two roe deer (Capreolus pygargus and C. capreolus) populations respectively (Randi et al. 1998); nucleotide differences ranged from 0.4 to $1.8 \%$ in a $6000 \mathrm{~km}^{2}$ habitat of eastern lowland gorillas (Gorilla gorilla, Saltonstall et al. 1998); sequence divergence ranged from 0.8 to $1.8 \%$ in eastern gorillas (JensenSeaman and Kidd 2001); nucleotide diversity ranged from 0 to $1.7 \%$ in Australian bush rats (Rattus fuscipes greyii, Hinten et al. 2003); and sequence divergence (from PCR-RFLP of control region) in several long-tailed macaque (M. fascicularis) populations ranged from 0 to $1.03 \%$ (PerwitasariFarajallah et al. 2001). Genetic distances among Shoushan macaques (up to $6 \%$ ) were much higher than these reported cases but were similar to what was reported in other macaque species at interpopulational level $(0.6-4.3 \%$ in $M$. fuscata, Hayasaka et al. 1991, 1.72-4.49\% in M. fascicularis, Perwitasari-Farajallah et al. 2001). Therefore, the origin of the diverse genetic makeup of the Shoushan population deserves further discussion.

The predominance of $S 1$ among social troops clearly indicates that $S 1$ is native in Shoushan. However, the native status of the other 12 haplotypes is questioned. Haplotypes S2 and S3 found in females of two large troops, SB and SC (estimated troop sizes are 40 and 70 , respectively), may be either native or have derived from non-native females that were successful at reproducing. Among the 10 male-specific haplotypes, S4-S6 and S9 differed from S1 and S3 by only one or two nucleotide changes (Figure 2). They may have derived from mtDNA matrilines not revealed in this study due to incomplete sampling of troops (four of the 16 troops were not sampled), or from populations near Shoushan. Other male-specific mtDNA haplotypes $(S 7-S 13)$ that are distant to S1 may have derived from populations further away from Shoushan. These males are most likely to be escaped or released captives. Male-biased captive release is a reasonable explanation because captive male M. cyclopis become hard to manage once attaining puberty and cases of monkey release are frequently reported in Taiwan (Lee et al. 2002).

In this study, we demonstrate by mtDNA sequence analysis the impact that escaped and released animals can have in the diversity of a natural population. The fact that some monkeys are exotic to Shoushan brings up an interesting and difficult conservation/management issue that should be considered. The introduction of foreign macaques may alleviate inbreeding risk in the isolated Shoushan population. However, it may also intensify human-monkey conflicts such as 
food raiding or crop damaging if the released macaques have prior experiences with humans. This situation poses management concerns. In addition, our study provides empirical evidence of anthropogenic genetic input that may also occur in other populations.

\section{Preserving samples by STE buffer}

In this research, PCR successfully amplified the mtDNA control region from all the hair samples and $68 \%$ of the fecal samples on the first attempt. The success rate of excremental PCR is similar to that reported elsewhere (e.g. Frantzen et al. 1998). Fecal DNA tends to degrade during storage, which would inhibit enzymatic manipulation, such as PCR (Deuter et al. 1995, Kohn et al. 1995). However, collecting fecal samples from wild animals is easier than capturing animals for conventional tissue samples. Moreover, capturing and handling would cause severe perturbation of the studied animals and, when working with non-human primates, would risk losing acceptance of habituated animals (Gerloff et al. 1995).

Various preservation methods for fecal samples have been reported (Höss et al. 1992, Constable et al. 1995, Gerloff et al. 1995, Kohn et al. 1995, Foran et al. 1997, Reed et al. 1997, Taberlet et al. 1997, Wasser et al. 1997, Frantzen et al. 1998, Murphy et al. 2002). We found that using STE buffer and ethanol provides a simple alternative. Fecal DNAs performed well in terms of quantity and quality when extracted within 3 weeks after collection. It is also possible to amplify mtDNA segments as long as $1.4 \mathrm{~Kb}$ even when samples have been preserved for more than 6 months before extraction. Therefore, we recommend this method for fecal sample preservation.

\section{Acknowledgements}

The authors would like to acknowledge KF Lin, SM Chen, and MW Fan for their assistance of sample collection. Many thanks to Professor Osamu Takenaka of the Primate Research Institute, Kyoto University, Japan, and Dr Yi-Ju Yang for valuable experimental advise; Dr. Adiran Isaacs and Miss Meng-Lan Yuan for proofreading the manuscript. GCG program service is kindly provided by National Healthy Research Institutes
(NHRI) in Taiwan. The research was supported by National Science Council, Taiwan (NSC-89-2311B-002-031) and the fund of the Institute of Zoology, Academia Sinica to HYW.

\section{References}

Avise JC, Arnold J, Ball RM, Bermingham E, Lamb T, Neigel JE, Reeb CA, Sounders NC (1987) Intraspecific phylogeography: the mitochondrial bridge between population genetics and systematics. Annl. Rev. Ecol. Syst., 18, 489-522.

Chu JH, Wu HY, Yang YJ, Takenaka O, Lin YS (1999) Polymorphic microsatellite loci and low-invasive DNA sampling in Macaca cyclopis. Primates, 40, 573-580.

Constable JJ, Packer C, Collins DA, Pusey AE (1995) Nuclear DNA from primate dung. Nature, 373, 393.

Deuter R, Pietsch S, Hertel S, Müller O (1995) A method for preparation of fecal DNA suitable for PCR. Nucleic Acids Res., 23, 3800-3801.

Dittus WPJ (1988) Group fission among wild Toque macaques as a consequence of female resource competition and environmental stress. Anim. Behav., 36, 1626-1645.

Fooden J, Wu HY (2001) Systematic review of the Taiwanese macaques, Macaca cyclopis Swinhoe, 1863. Fieldiana: Zoology, n.s., 98.

Foran DR, Crooks KR, Minta SL (1997) Species identification from scat: an unambiguous genetic method. Wildl. Soc. Bull., 25, 835-839.

Frantzen MAJ, Silk JB, Ferguson JWH, Wayne RK, Kohn MH (1998) Empirical evaluation of preservation methods for faecal DNA. Mol. Ecol., 7, 1423-1428.

Gerloff U, Schlötterer C, Rassmann K, Rambold I, Hohmann G, Fruth B, Tautz D (1995) Amplification of hypervariable simple sequence repeats (microsatellites) from excremental DNA of wild living bonobos (Pan paniscus). Mol. Ecol., 4, 515-518

Hayasaka K, Ishida T, Horai S (1991) Heteroplasmy and polymorphism in the major non-coding region of mitochondrial DNA in Japanese monkeys association with tandemly repeated sequences. Mol. Biol. Evol., 8, 399-415.

Hinten G, Harriss F, Rossetto M, Braverstock PR (2003) Genetic variation and island biogeography: microsatellite and mitochondrial DNA variation in island populations of the Australian bush rat, Rattus fuscipes greyii. Conserv. Genet., 4, 759-778.

Hoelzer GA, Dittus WPJ, Ashley MV, Melnick DJ (1994) The local distribution of highly divergent mitochondrial DNA haplotypes in toque macaques Macaca sinica at Polonnaruwa, Sri Lanka. Mol. Ecol., 3, 451-458.

Höss M, Kohn M, Knauer F, Schröder W, Pääbo S (1992) Excrement analysis by PCR. Nature, 359, 199.

Hsu MJ, Lin JF (2001) Troop size and structure in free-ranging Formosan macaques (Macaca cyclopis) at Mt. Longevity, Taiwan. Zool. Stud., 40, 49-60.

Jensen-Seaman MI, Kidd KK (2001) Mitochondrial DNA variation and biogeography of eastern gorillas. Mol. Ecol., 10, 2241-2247.

Kawamoto Y, Shirai K, Araki S (1999) A case of hybridization between the Japanese and Taiwan macaques found in Wakayama Prefecture. Primate Res., 15, 53-60.

Kawanaka K (1973) Intergroup relationships among Japanese monkeys. Primates, 14, 113-159. 
Kimura M (1980) A simple method for estimating evolutionary rates of base substitutions through comparative studies of nucleotide sequences. J. Mol. Evol., 16, 111-120.

Kocher TD, Thomas WK, Meyer A, Edwards SV, Paabo S, Villablanca FX, Wilson AC (1989) Dynamics of mitochondrial DNA evolution in animals: Amplification and sequencing with conserved primers. Proc. Natl. Acad. Sci. $U S A$, 86, 6196-6200.

Kohn M, Knauer F, Stoffella A, Schröder W, Pääbo S (1995) Conservation genetic of the European brown bear - a study using excremental PCR of nuclear and mitochondrial sequences. Mol. Ecol., 4, 95-103.

Kumar S, Tamura K, Jacobsen I, Nei M (2000) MEGA2: Molecular Evolutionary Genetics Analysis, version 2.0. Pennsylvania and Arizona State Universities, University Park, PA and Tempe, AZ.

Lee LL, Wu HY, Chang SW, Hsu MJ, Agoramoorthy G (2002) Survey on current status of Formosan macaques. In: Report of the Symposium on Conservation and Management of Formosan Macaques, pp. 34-48. Society for Wildlife and Nature, Taiwan

Lin HY (1997) A comparative study on intestinal parasites of Taiwan macaques (Macaca cyclopis). Master thesis. National Taiwan University (in Chinese), Taipei, Taiwan.

Masui K, Narita Y, Tanaka S (1986) Information on the distribution of Formosan monkeys (Macaca cyclopis). Primates, 27, 383-392.

Melnick DJ, Hoelzer G (1992) Differences in male and female macaque dispersal lead to contrasting distributions of nuclear and mitochondrial DNA variation. Int. J. Primatol., 13, 379-393.

Murphy MA, Waits LP, Kendall KC, Wasser SK, Higbee JA, Bogden R (2002) An evaluation of long-term preservation methods for brown bear (Ursus arctos) faecal DNA samples. Conserv. Genet., 3, 435-440.

Nagata J, Masuda R, Tamate HB, Hamasaki S, Ochiai K, Asada M, Tatsuzawa S, Suda K, Tado H, Yoshida MC (1999) Two genetically distinct lineages of the sika deer, Cervus nippon, in Japanes Islands: comparison of mitochondrial d-loop region sequences. Mol. Phylogenet. Evol., 13, 511-519.

Perwitasari-Farajallah D, Kawamoto Y, Kyes RC, Lelana RPA, Sajuthi D (2001) Genetic characterization of long- tailed macaques (Macaca fascicularis) on Tabuan Island, Indonesia. Primates, 42, 141-152.

Pusey AE, Packer C (1987) Dispersal and philopatry. In: Primate Societies (eds Sumts BB, Cheny DL, Seyfarth RM, Wrangham RW, Struhsaker TT), pp. 250-266. University of Chicago, Chicago, IL

Randi E, Pierpaoli M, Danilkin A (1998) Mitochondrial DNA polymorphism in populations of Siberian and European roe deer (Capreolus pygargus and C. capreolus). Heredity, 80, $429-437$.

Reed JZ, Tollit DJ, Thompson PM, Amos W (1997) Molecular scatology: the use of molecular genetic analysis to assign species, sex and individual identity to seal faeces. Mol. Ecol., 6, 225-234.

Saltonstall K, Amato G, Powell J (1998) Mitochondrial DNA variablity in Grauer's gorillas of Kahuzi-Biega National Park. J. Hered., 89, 129-135.

Swofford DL (1999) PAUP 4.02: Phylogenetic Analysis Using Parsimony. Illinois Natural History Survey, Champaign, IL.

Taberlet P, Camarra JJ, Griffin S, Uhres E, Hanotte O, Waits LP, DuboisPaganon C, Burke T, Bouvet J (1997) Noninvasive genetic tracking of the endangered Pyrenean brown bear population. Mol. Ecol., 9, 869-876.

Taberlet P, Meyer A, Bouvet J (1992) Unusual mitochondrial DNA polymorphism in two local populations of blue tit Parus caeruleus. Mol. Ecol., 1, 27-36.

Wang CL, Ni IH (2000) Population dynamics of the feral macaques in the Kowloon Hills of Hong Kong. Am. J. Primatol., 50, 53-66.

Wasser SK, Houston CS, Koehler GM, Cadd GG, Fain SR (1997) Techniques for application of faecal DNA methods to field studies of Ursids. Mol. Ecol., 6, 1091-1097.

Wu HY, Lin YS (1992) Life-history variables of wild troops of Formosan macaques (Macaca cyclopis) in Kenting, Taiwan. Primates, 33, 85-97.

Wu HY, Lin YS, Lee LL (1991) Demography of a wild troop of Formosan macaque in Kenting, southern Taiwan. In: Primatology Today (eds Ehara A, Kimura T, Takenaka O, Iwamoto M), pp. 29-32. Elsevier, Amsterdam.

Yoshimi I, Takasaki H (2003) Long distance mobility of male Japanese macaques evidenced by mitochondrial DNA. Primates, 44, 71-74. 